\title{
DID GRACE KELLy SHED A TEAR?
}

\section{THE MONEGASQUE ROYAL WEDDING ASA DISRUPTIVE TELEVISION EVENT}

\author{
John Ellis \\ Professor of Media Arts \\ Royal Holloway University of London \\ Egham \\ Surrey TW20 0EX \\ United Kingdom \\ John.Ellis@rhul.ac.uk
}

\begin{abstract}
Early television reveals the radical nature of the new medium as well as many of its affordances that were later rejected. The coverage of the Monegasque Royal Wedding of Prince Rainier of Monaco and Grace Kelly exposes the differences between cinema newsreels and live TV, and how, even at a public event, TV could invade the personal space of its subjects. Like a detective, the author reconstructs how this historical event was covered by film and TV, and how that footage was later re-used. The montage of the footage in different contexts encourages the audience to suppose that Grace Kelly might have shed a tear during the wedding ceremony. While this question might seem ridiculous to a republican, it is important for our understanding of celebrity in modern culture. The author's answer to the question reveals the media historical meaning of both the media event, its coverage and the possible existence of that tear.
\end{abstract}

Keywords: television event, live television, royal wedding, Grace Kelly, Prince Rainier of Monaco, intimacy, archival footage, access

\section{Introduction}

The coming of television brought a drastic change in visibility and proximity. Live television enabled sustained observation. Meyrowitz presented an optimistic view of this affordance in 1985 when he wrote that "[t]he president of the United States showed his operation scars to the nation as if all the people in the country were his intimate friends." ${ }^{1}$ He saw television as enabling the flow of information between groups that had traditionally been isolated from each other by geography, social class, age, gender, ethnicity, indeed almost all of the distinctions that animate (or disfigure) the modern world. In this quotation, he identifies the person-to-person aspect of television, the ability to 
communicate, as Scannell put it, "to anyone as someone". ${ }^{2}$ Meyrowitz (unlike Scannell) identifies the effect of social levelling that is involved in this operation. Meyrowitz is anxious that the 'office of the president' might be demeaned, even as the person of the president engages directly with the people who elected him. There is such a thing as 'too close', as we might say. ${ }^{3}$

Elsewhere in No Sense of Place, he discusses the spatial aspects of this television revolution, the other side of this "too close". Television brings us closer to individuals and breaks down the traditional divisions between public and private as well as the far and the near. Television can even bring us closer to an event or a person than an individual could in real life. Live television (and most of what was shown in the early years was live) could also bring us the complete event and not just edited highlights. So the television industry quickly discovered that certain kinds of sport provided ideal content: not only was sport inexpensive, as William Paley points out, but sporting events also take place in a defined space where the cameras could be set up in advance to provide hours of material. Even better were sports that involved a clear competition between two forces: baseball, football and hitherto marginal sports like tennis. As Lord Orr-Ewing says, Wimbledon became a fixture of the early post-war BBC calendar, and has remained there ever since. Television enabled huge audiences to follow sporting events, providing coverage as they happened. The matches were easy to understand visually because TV simply adopted the visual grammar that had been developed in cinema: the 180 degree rule. Events were shot from the same side as though they were taking place on a stage, so direction of movement was always clear to the viewers. Soon zoom lenses allowed the use of close-ups as well. ${ }^{4}$ Television effortlessly acclimatised society to one of its key differences from cinema: it was a mechanism that allowed watching in a sustained way. It could reveal a whole event as it unfolded in time.

This characteristic was a great advantage where sport was concerned, but politics and public affairs found it altogether more of a problem. The British parliament did not allow TV cameras to show its proceedings until November 1989, over fifty years after the first regular TV broadcasts by the BBC. The objections "were technical, reputational, party political and procedural" ${ }^{5}$ according to Franklin, ranging from the heat of the necessary lights to the idea that parliament so lacked in entertainment that only short extracts would be used to 'spice up' the news. In this article, I examine in detail an example of television coming too close at a moment of high ritual: a royal wedding.

\section{The Royal TV Event as National Ceremonial: United Kingdom 1953}

Royal families had fewer qualms about the new medium of television than were entertained by the British parliament. They realised (like Meyrowitz's American president) that their continued survival in the democratic era depended on using the media to create a close relationship with their public. In the UK, the publicity disaster of Edward VIII's abdication had been more than compensated for by the role played by his successor George VI and his family during the Second World War. Remaining in London throughout the Blitz, touring bombed areas, they were popularly credited with providing a fine public example. The young princesses, Elizabeth and Margaret, were a key part of this concerted media campaign. So when the time came for Elizabeth to be crowned, it was a natural decision that the whole event should be covered by the BBC. The televising of the coronation in 1953 was a major event. It stimulated sales of TV sets and made television respectable for the first time. There was a minimal and respectful commentary, with just the right amount of gravitas, from Richard Dimbleby. The cameras were stationed along the route of the procession and in

2 Paddy Scannell, 'For-anyone-as-someone structures,' Media, Culture \& Society, 22,1, 2000, 5-24.

3 Meyrowitz, No Sense of Place, p. $268 \mathrm{ff}$.

4 Nick Hall, The Zoom: Drama at the Touch of a Lever, Rutgers University Press, 2018.

5 Bob Franklin, 'Televising the British House of Commons: issues and developments,' in: Bob Franklin, ed, Televising Democracies, Routledge, 1992, 3-26. 
Westminster Abbey itself. The TV coverage was planned as meticulously as the event itself. But there was one basic rule: no close-ups of the Queen herself, a rule that was infringed but not exactly broken by the BBC.

For the coronation of Queen Elizabeth, one of the characteristics of the new medium was exploited to the full. The viewing public could participate at a distance in the duration, the sounds and the sights of the event. But another characteristic, just as revolutionary and disruptive, was forbidden. It was impossible to study the faces of the individuals involved.

\section{The Royal Wedding as Relaunch: Monaco 1956}

No such constraints were imposed on the next televised royal event, one that sealed the alliance between the crowned heads of Europe and the moguls of the new entertainment industry. When Prince Rainier of Monaco married Grace Kelly, the star of three Hitchcock films, television was more thoroughly involved in the conception of the event, and the coverage more clearly demonstrates why TV was a great step forward for audiovisual media.

Monaco is a tiny state on the Mediterranean, just two square kilometres entirely surrounded by France. Its harbour was even too small to accommodate the ship that brought Grace Kelly from the USA. It depended for its income on its casino and its liberal tax regime, and business had not been so good since the 1929 stock market crash. This did not please the key shareholder Aristotle Onassis. Monaco had also not fully recovered from its difficult time in the Second World War, when continuing independence had been assured only at the cost of giving up most of its Jewish community to the Nazis. Moreover, the ruling Grimaldi dynasty needed a male heir to prevent the territory from being absorbed into France according to the terms of its independence treaty. So Prince Rainier's marriage to a film star presented solutions to many problems, which the couple shrewdly exploited.

Grace Kelly, daughter of a wealthy brick tycoon and Democrat politician, had the confidence to break her contract with MGM. To show that there were no hard feelings, MGM presented her with her wedding dress, designed by Helen Rose. MGM knew that the publicity would do no harm to the film that Kelly had just completed, The Swan, not uncoincidentally 'the love story of a princess'. They sent a publicist and a hairdresser over to Monaco with her to make sure that she looked her Hollywood best. The event was planned to generate the maximum publicity for all concerned, and attracted over 1500 journalists to Monte Carlo whose population numbered around 4000.

Rainier, for his part, saw that the wedding could be used to launch a new enterprise for his tiny principality: television. He refused to allow the movie newsreels to dominate the occasion, giving exclusive rights to show the civil ceremony to French state monopoly TV organisation ORTF and his new private company Tele Monte Carlo. On 18 April, it was broadcast over the new Eurovision system and was watched by an estimated 30 million people in nine European countries, at 10.45 in the morning (9.45 in the UK). This civil ceremony merely changed Miss Kelly to Mrs Grimaldi. A cathedral ceremony, at ten o'clock the next day, created her as Princess Grace of Monaco. This second ceremony was watched by a Eurovision audience of similar size to the first. The BBC feasted on the coverage, showing both the civil and the cathedral ceremonies as well as an hour of the Festival Serenade (17 April 8pm-9pm), and an hour of the Soiree de Gala on 18 April (7.45 to 8.45).

The civil ceremony was a TV exclusive, taking place in the rather restricted space of the palace throne room. For the cathedral ceremony, the newsreel cameras were allowed in, but with a contract that allowed them to use only two minutes of footage from inside the building. Grace Kelly's former employers MGM were allowed three cameras of their own. The ceremonies had to be shown live as videotaping had not yet been introduced (coincidentally the first two inch machines were being demonstrated to the TV trade by Ampex in the USA during this same month). By the standards of today's television industry, the decision to hold both ceremonies in the morning is an odd one. It meant broadcasting to a daytime audience in Europe, and would have definitively ruled out a simultaneous US transmission. But then in 1956, a transatlantic TV link was still a dream. It did not come about until 1962. So the USA had to content 
J. Ellis, Did Grace Kelly Shed a Tear?

itself with film coverage: newsreels and a 30 minute colour documentary produced by MGM. Only Europe had the privileged of watching the live TV coverage.

\section{A Cathedral Full of Cameras (and Priests as sound Assistants)}

The cathedral wedding demonstrates the revolutionary potential of television, and how much it differed from cinema. The key camera position was behind the altar, from where the faces of both Rainier and Grace could be filmed. There were three cameras placed there: one for TV, one for the newsreels and one for MGM. This still from an excellent Arte documentary about the event, takes a still frame and highlights the shadowy figures of the camera crews, partially concealed by a bank of flowers.

A total of ten cameras were placed in the cathedral: four for TV, three for MGM, and three for the newsreel companies. Television had the best positions, two shooting from the North side of the cathedral, the side on which Grace Kelly would kneel, the central position from behind the altar (enabling the best close-ups of both Grace and Rainier), and a fourth camera beside the altar on the south side which would give an oblique frontal shot of the couple, an angle that none of the other cameras could get.

\section{The Newsreel View}

The two British newsreel companies, Pathe and Movietone, ended up by showing less than their two minutes' ration of footage from the cathedral. Pathe ran a three and a half minute item with just less than half showing events inside

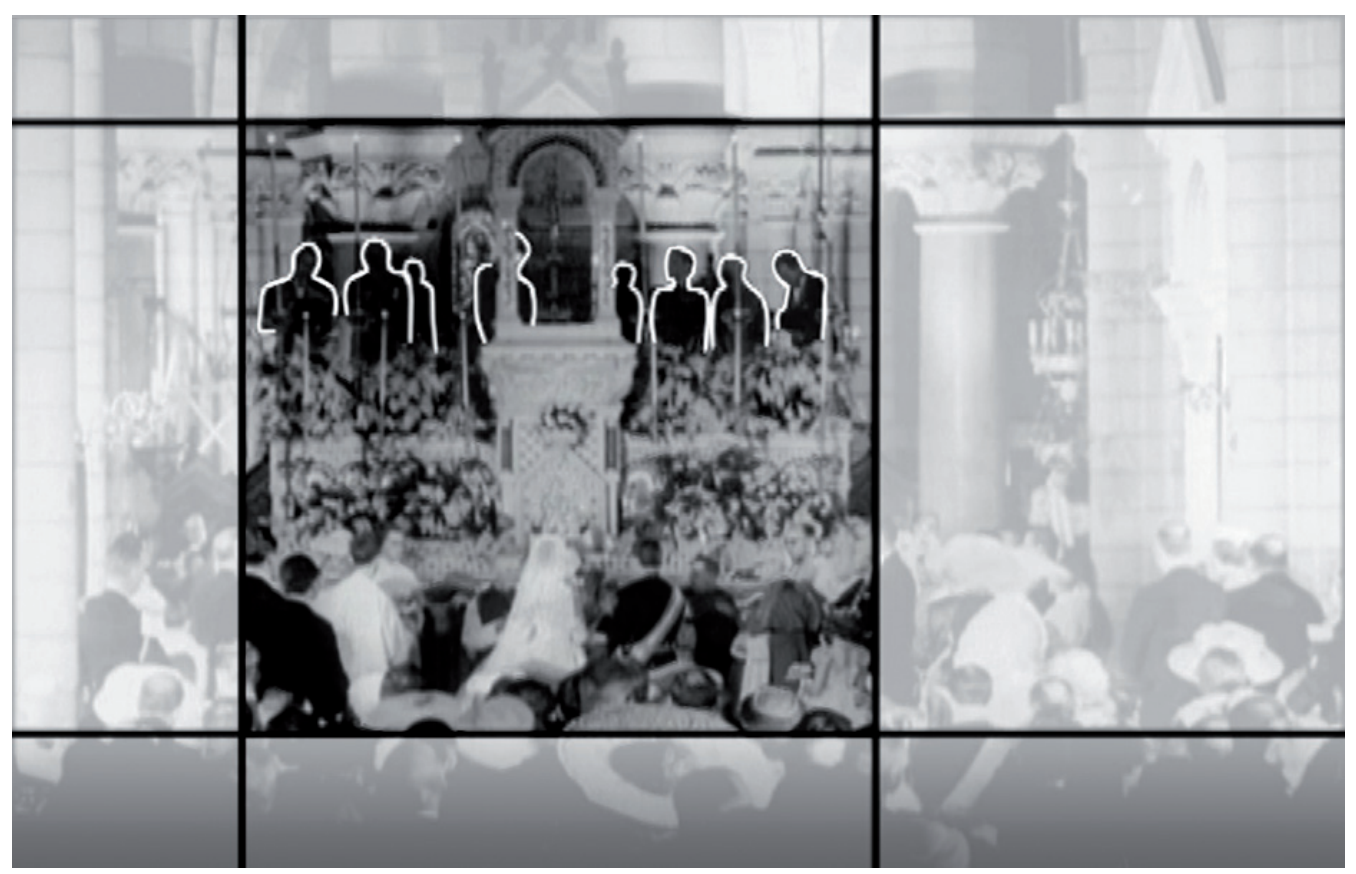

Figure 1. A technical rehearsal took place before the event so that the lighting would clearly illuminate the groom and bride in her ivory dress. Microphone positioning was particularly important for the TV coverage, and priests were recruited to move them when necessary. 


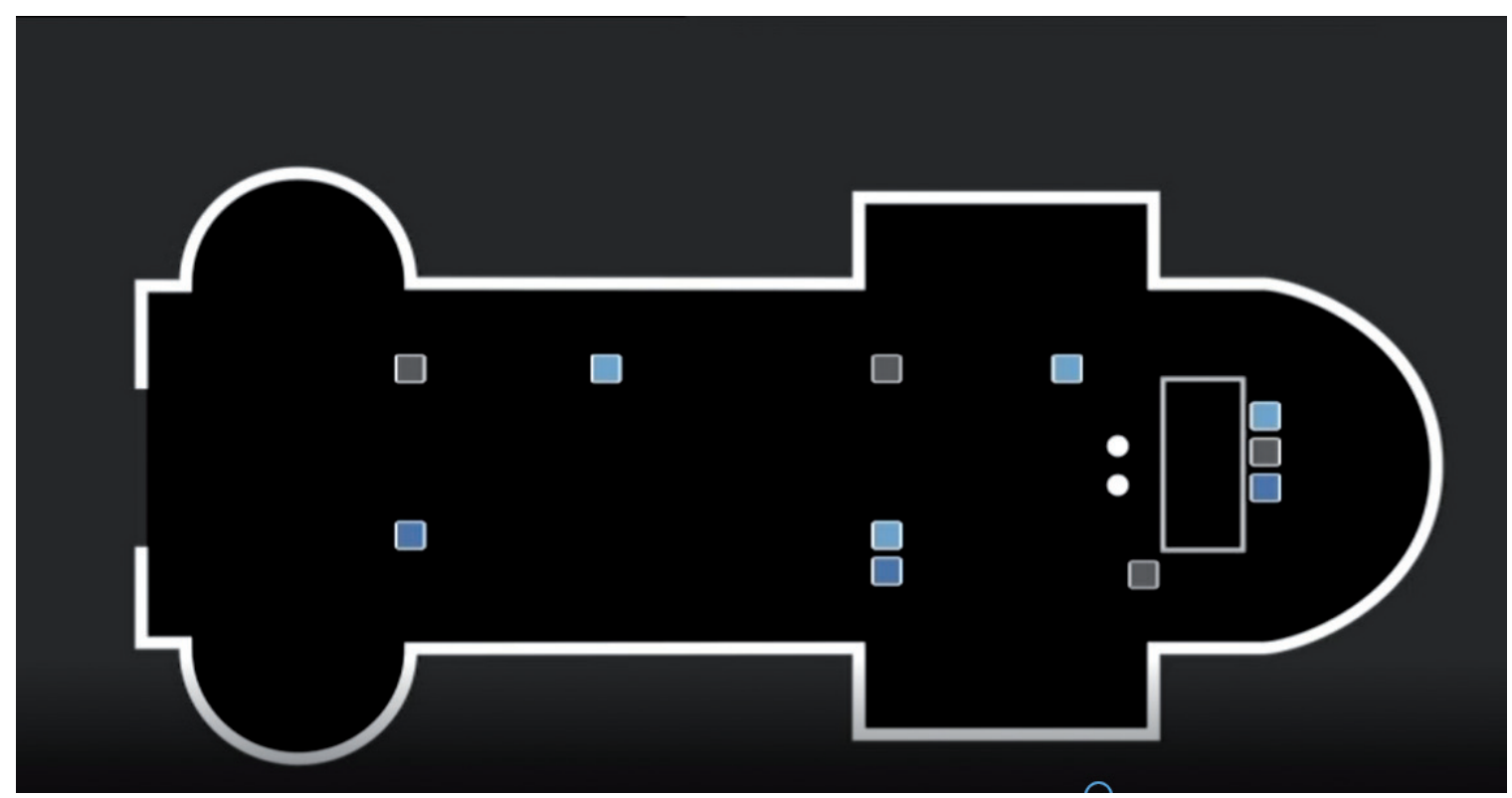

Figure 2. Camera positions in the cathedral: TV cameras in grey, cinema newsreel pool cameras light blue; MGM dark blue.

the cathedral. Movietone's item is longer at four and a half minutes but it spends just a minute inside cathedral, with the commentary remarking that 'Princess Grace's title 'Serene Highness' was well borne out by her solemnity throughout the long marriage service", throwing a distinct emphasis on the word 'long' as if to indicate that it was all rather boring. Both share the same single close-ups of Rainier and Grace in the cathedral. Other newsreels have better selection of shots, but all follow the same strategy. They present a compilation of glimpses of the whole event, held together 1 by a voice-over narration that stresses its fairy tale nature. The sounds of the event are therefore secondary, an assemblage of snatches of liturgical music, fanfares and cheering crowds, and the voice of the bishop reciting Grace Kelly's vow, revealing Rainier's impressive list of personal names.

\section{The Television View}

The television footage is entirely different. As a result of Lisa Kerrigan's article in VIEW ${ }^{6}$ we know of a remarkably early example of television's use of its own archives. But her article does not remark on the close-up of Grace Kelly at all: it pursues another interesting avenue, exploring the series as a whole, and the existence of 'archival' programming of television material long before it might have been expected. It was not until Lisa presented this one particular episode to the Southern Broadcast History Group that I encountered the TV footage of the wedding directly. The episode has been digitised and is available through the British Film Institute, but can only be consulted at their premises since it is restricted in this way by a blanket agreement with the BBC. There seems to be no particular underlying copyright or other reason why this archival programme of factual material should be so restricted. However, this is quite a common feature of releases of archival television: blanket agreements can be reached where releases on an item-by-item basis would be impossibly time consuming.

Plunder allows the viewer to appreciate just how radical the television coverage of the wedding was compared to the newsreels' formulaic coverage. In 1966 a programme on the new BBC2 was devoted to archive footage 
(recycling came early to TV), and the 16 April 1966 edition of Plunder shows a ten and a half minute chunk from the cathedral ceremony itself. This was an extract from the live TV footage of 1956. It had been recorded onto film using a Cinetele machine, the only method then available for recording video signals. The presenter Michael Raper warns us that the sudden bursts of noise on the soundtrack are the sound of a film camera recording the event. We are some minutes into the ceremony before we hear this sound, and have almost forgotten his warning. When it comes, it is loud indeed, the sound of a $35 \mathrm{~mm}$ camera with little or no noise suppression or blimping. It must have been the newsreel camera positioned right beside the TV camera as MGM's colour footage is shot from a more oblique angle. This newsreel camera is clearly recording only pictures, with no synch sound. The newsreels that were released confirm that this was the case, as they carry no sync sound from the cathedral.

This newsreel camera runs for just 50 seconds during a ten minute section that the TV cameras show in full. It captures only those moments that were likely to be used in the newsreel format. It gets the twenty seconds of Grace Kelly's vow followed by the blessing of their intertwined hands; it gets the half minute of the couple putting the rings on each other's fingers, with Rainier making a bit of a fumble. And that's it. The event has already been pre-edited in camera, avoiding the waste of expensive film on shots that would probably not be used.

The contrast between the work done by the two cameras next to each other is remarkable, and tells us much about the shock of the new which television produced. The television camera is on all the time, with the programme cutting live to the output of other cameras according to the pace of the event. The sound is the sound of the event, with no additions (apart from a sparse commentary) and very little mixing. Once the prince and future princess have arrived at the altar (Grace, the commoner, arrives first), the one camera on their faces alternates with a number of others on each side of the nave of the church, showing their backs and concentrating, in longer shot, on the activities of the officiating priests.

But the bulk of the time is taken by the camera on the bride and groom, and it tends to concentrate on Kelly. She is in close-up for almost a third of the ten minute extract shown by Plunder in 1966. The camera moves freely between Grace and Rainier, picking out details such as the placing of the rings. We see a shot of the boy pages who held the cushion with the ring fidgeting about once his role has been played. And most remarkably, the camera dwells at one point on Grace Kelly's face for a full minute and a half. This is a remarkable moment which has wide implications for our understanding of the power of television to change perceptions, and how that potential was used in television's formative years.

\section{Did Grace Kelly Cry...?}

And what does Grace Kelly, her Serene Highness, actually do during this shot? She is listening, as we are, to the choir singing the Benedictus, with an orchestral accompaniment, a solemn piece that is the culmination of this Catholic mass and wedding celebration. The vows have been exchanged; the rings have been placed on the fingers and mass is reaching its conclusion. The movie cameras have taken what they needed from the event. But television ploughs on, showing us the newly minted Princess Grace as she looks forward, her face expressionless, her mouth unmoving. Her eyes move to her left, she drops her head slightly, she looks up again and swallows. She drops her head again and swallows once more. Then the choir's performance ends.

Does a tear begin to form in her eye? At this historical distance, looking at a digitised film of the signal from a TV screen in 1956, it is impossible to tell. The image is hardly a sharp one.

But the editing of the extract in Plunder indicates that she does. After the long close-up shot, there is a sudden cut to a wide shot from the camera on the south side of the cathedral, a camera whose output has not appeared in this extract so far. Most of the coverage shown in the Plunder extract has favoured Grace, so has used cameras on the north side 


\section{VIEW}

J. Ellis, Did Grace Kelly Shed a Tear?

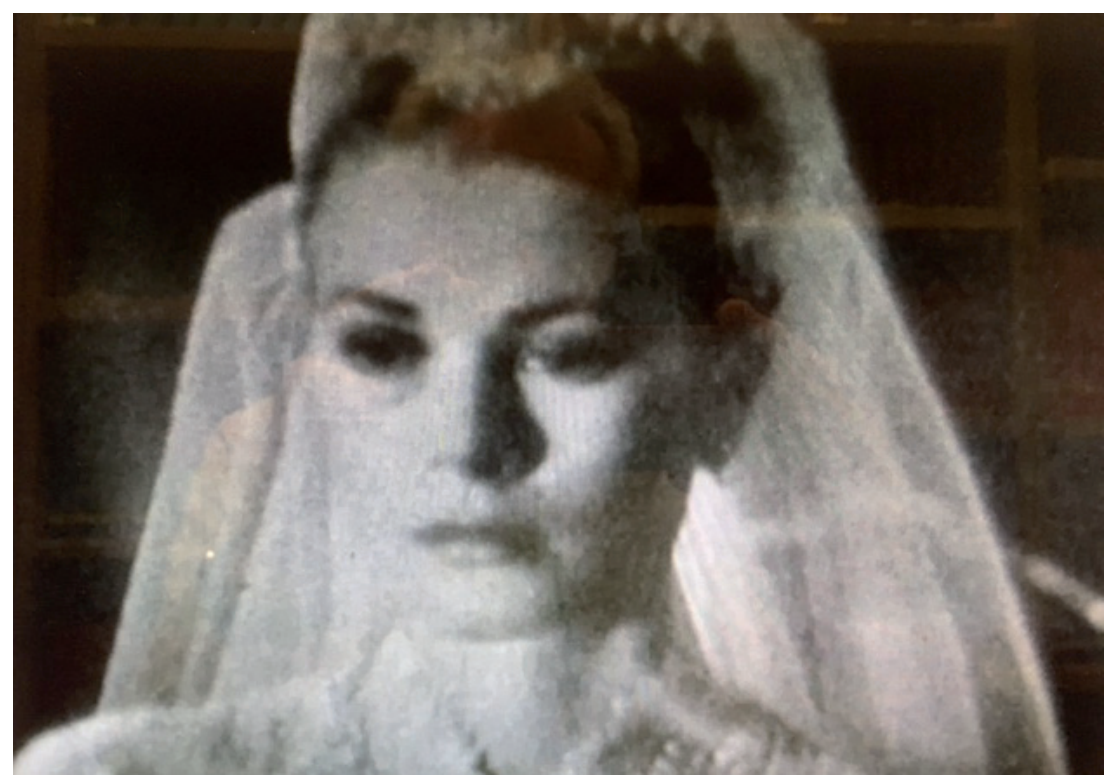

Figure 3. Close-up of Grace Kelly during the ceremony as covered by television; screenshot of the 16 April 1966 edition of BBC2's Plunder.

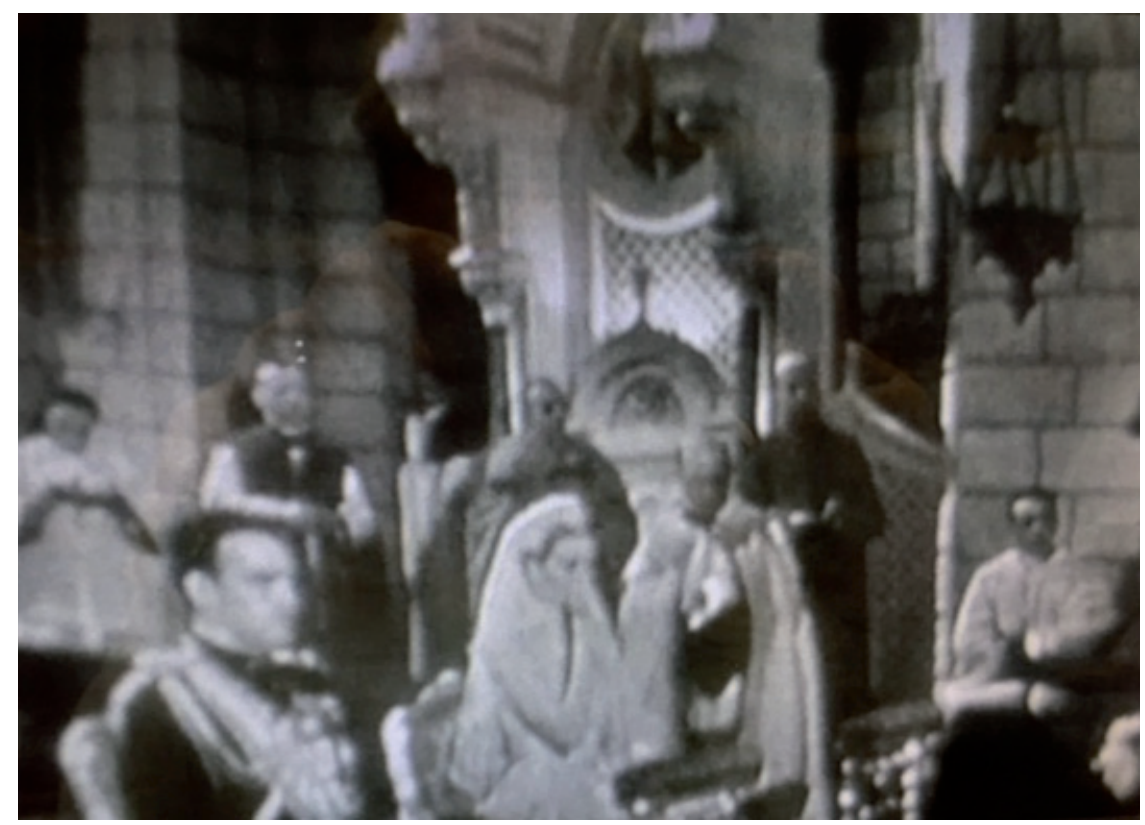

Figure 4. Grace Kelly her dabbing at her eye with a handkerchief during the ceremony as covered by television; screenshot of the 16 April 1966 edition of BBC2's Plunder.

of the cathedral, and the key one behind the altar. This one shows the couple from an oblique frontal angle with Grace in the centre of shot. From this new angle, we can see her dabbing at her eye with a handkerchief.

After four seconds, the coverage cuts back to the close-up of Grace, but this time the camera pans down to catch her action of replacing the handkerchief into her left sleeve, and then up again to her face. Princess Grace has been caught out in an intimate moment in her own wedding ceremony. After a few seconds the TV coverage remembers the decorum of the event and cuts back to the activity of the priests as they continue to conclude the ceremony. 


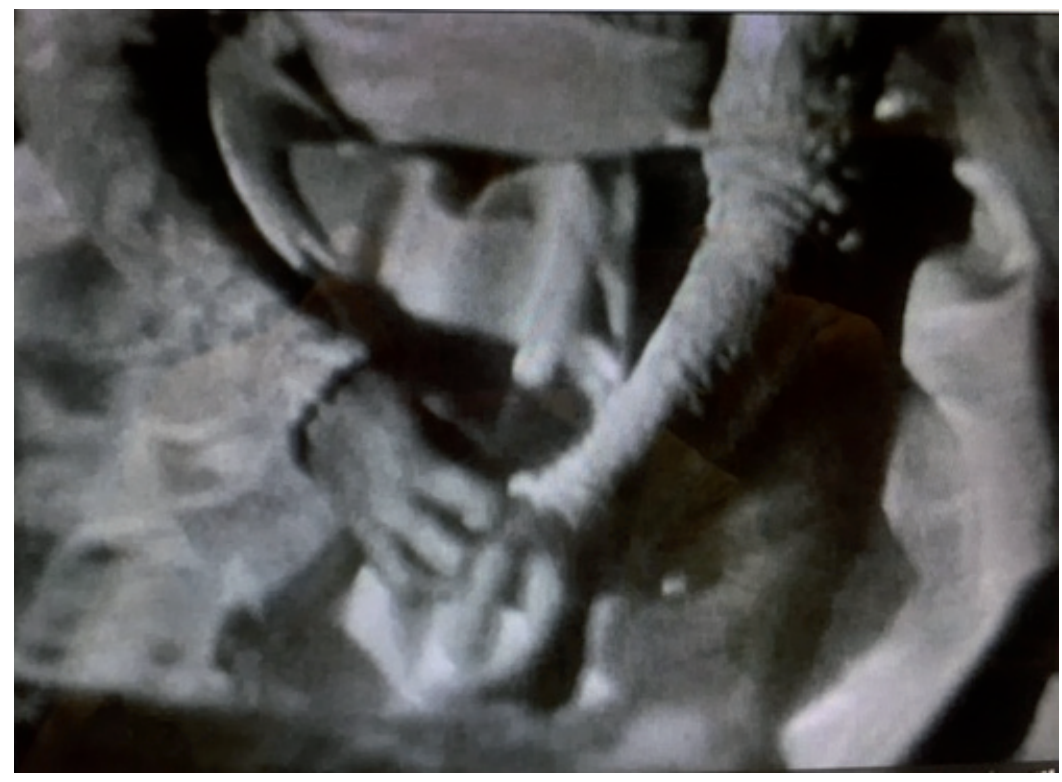

Figure 5. Grace Kelly replacing the handkerchief into her left sleeve during the ceremony as covered by television; screenshot of the 16 April 1966 edition of BBC2's Plunder.

\section{$8 \ldots$.... Or idn't She?}

At least, this is what happens in the footage shown in BBC2's Plunder programme. But it turns out that the programme makers at the BBC had edited the original archive recording. The telerecording of the whole ceremony does still exist, despite the fact that nothing from it appears in the Arte documentary about the coverage of this royal wedding. The entire hour and 40 minutes of the original French broadcast, directed by Pierre Sabbagh and narrated by Claude Darget. It can be found in the INA archive, reference CPF86611535. But it is not available for a general user. It can be accessed only by a researcher acting as a member of the broadcasting industry: the INA Media Pro service. When I signed up for this, I immediately discovered that the makers of Plunder had abbreviated the original footage quite considerably. They omit the entire mass which comes after the exchange of rings. They also omit the signing of the marriage register, for which television had no pictures as the signal was lost for about a minute. They omit footage of two fidgeting pageboys who are clearly unawed by the ceremony in which they play the important role of passing on the rings.

Most remarkable of all, the Plunder producers have cut down the long close-up of Grace Kelly. In the original footage, it lasts for two minutes and 16 seconds (timecode 01:07:54 to 01:10:08). And they have also recut the transition out of this shot, which follows Princess Grace as she sits at the end of the Benedictus, looking briefly across to Prince Rainier. A shot of the officiating priests from behind the couple follows lasting 9 seconds. Then we see the oblique shot of the couple (which has featured regularly throughout the service) for three seconds (as in the Plunder version) and then return to the close shot of Princess Grace panning down to show her replacing the handkerchief in her cuff.

It is clear that Princess Grace does not wipe her eye directly. It is also clear, from this better defined footage, that her eyes begin to glisten as we watch her face in the seemingly interminable close-up. So the ambiguity of the tear remains, and is still a matter for each viewer to decide, according to their preferences. 
Whatever that viewer decides, they will have had to watch a close-up of over two minutes duration, the only instance of such a long close-up in the entire broadcast. For a live television audience, this must have been a remarkable, if not unbearable, moment. To stare at someone for a minute and a half breaks all the rules of social exchange. It is not something that you can do to someone else, other than perhaps as lovers 'staring deep into each other's eyes'. Usually, it is an intrusion that makes the observed person anxious or angry or both. Television was giving its huge audience a privileged view, one that had not been available even in the movies that Grace Kelly had starred in before. The shot is far longer than an entertainment movie close-up could reasonably be.

This privileged view breaks a social taboo, and even a modern-day viewer can be taken aback by it, as I was when I first saw this footage. As the shot holds longer and longer, it requires the viewer to find reasons to justify their continued act of watching: of course she is a movie star, used to being watched; of course, this is a public performance, an event explicitly staged for public view to confirm the civil ceremony that has already taken place in private. So there is no intrusion into privacy; but there remains a feeling that this shot is too close and too sustained to be justifiable. In this moment, much more so than in the British coronation of 1952, television announced itself as a novel disrupter of the visual status quo.

Viewers at the time had possibly seen something unprecedented. There was no commentary to tell them, so probably many missed the significance of this unscripted moment. They might well have been rendered uncomfortable by the camera's sustained stare, and so have missed what it was showing, as I did when I first saw this footage. They might well have been distracted by other things going on in their domestic space, given that this was a live morning broadcast on 19 April 1956 at 9.00 on the BBC, and an hour later in most of Europe. That's another fact of domestic TV: just because TV shows something, it doesn't mean that anyone notices. But in this moment, television demonstrated that it was capable of rewriting the then well-established conventions of moving picture usage.

Grace Kelly is a woman who, as a film star, is used to being seen by cameras and was a familiar face to the viewers of the time. But the sustained attention of the TV camera is something else. It shifts the terms of looking, allowing a continued scrutiny of a face in close-up in a way that cinema did not offer. Kelly's is the face of someone who knows she is being watched and is behaving accordingly, but is nevertheless caught unawares.

Contrast this with the work of the newsreel camera, operating within a different aesthetic which, until then, had been assumed to be an adequate way of communicating news through moving pictures. Pictures functioned as the confirmation or proof of the event described in the relentless voice-over. The newsreel crew knew what they wanted: the key details only. They knew that extended shooting would be a waste of time and money as the footage would not be used. They operated with the assumption that commentary and background sound would be added in post-production to manufacture the newsreel story.

Television, however, showed the whole event. Claude Darget's commentary was sparse and did not explain the ceremony as it evolved, intervening only for the time when the loss of camera signal obscured the images of the signing of the register. The ceremony takes place in French and there is considerable choral music as well, all of it relayed to the television viewers. Live television has rethought the whole idea of observing a public event like this. It has dispensed with the selectivity of the newsreel, and it actively abolishes distance in a way that seems shocking even now. This is truly a new way of seeing.

Grace Kelly is not prepared for it, and neither, probably, was the morning time audience. This was a new medium being deployed in exceptional new circumstances. These first moments take place before conventions have had a chance to establish themselves. They showed the process of the Princess's tear welling up because they could show the Princess beginning to shed a tear; and the niceties of privacy and personal space, of politeness, of decorum, of ethics only come later in the development of the medium. 


\section{Between Then and Now}

These days, we are used to tears in television, of course. Tears are one of the markers of both stress and honesty. Tears are also one of the "money shots" of the popular talk show genre, defined by Laura Grindstaff in this way:

Ordinary people are expected to deliver what I call, borrowing from film pornography, the 'money shot' of the talk show text: joy, sorrow, rage, or remorse expressed in visible, bodily terms. ${ }^{7}$

She vividly describes her observation of one such show:

Diana, the show's host, prodded for more details, and Karen obliged, tears welling up in her big brown eyes. I could feel the tension rise in the control booth; we were simultaneously horrified by her suffering, incredulous that she would discuss it on national television, and elated that she was doing so with such visible emotion. ${ }^{8}$

When Karen cries, it is the result of an interview process, exchanges between two people of unequal power within a defined format. ${ }^{9}$ For Princess Grace, there was no interview. There is no conversational process that the viewers follow which ends in her shedding a tear. When the interviewee cries, then we viewers are prone to cry too. The conversation produces a sense of empathy, and empathy can lead us to sympathetic crying, or at least the sensation of tears forming: a lump in the throat, a glistening of the eye. With the long held shot of Princess Grace, we observe, but we cannot understand. We can only speculate about the emotions that Princess Grace may be feeling, reading in our knowledge of her situation.

This is why this long held shot remains a remarkable exception. It is a moment where television transgressed the limits of existing social practices. Many of television's early transgressive moments opened up the possibilities of dialogue about and through the emotions, leading eventually to the TV chat show. These moments often took place across class boundaries. ${ }^{10}$ However, this practice of extended close-up lead in a different direction, one that broadcast television chose not to follow through.

It opens up a vista of uncontrolled staring, of invasion of the privacy of an individual without their awareness of what is happening. It is voyeurism in the proper sense of the word, a sustained looking where the consent of the subject is flimsy at best. Princess Grace knew that she would be seen on TV, but not that it would be in this way. For the voyeur, there is the thrill of the subject's unawareness tempered by the permission for some kind of looking. This is the double-bind that leads a voyeur to tell the police officer arresting him "if they didn't want to be seen, then they would have drawn the curtain", a statement that acknowledges the transgression whilst denying it.

Such is the position that we viewers are put into by this long-held close-up. It feels uncomfortable. Indeed, it might even have been criticised within the French broadcaster ORTF as an error of judgement (as it would be now). Further research might discover evidence of this. However, we should note that the producers of BBC2's Plunder, a decade later, chose to retransmit the footage almost complete and without comment, so they, at least, were not overly concerned about 'disrespecting' living royalty (though not, of course, British royalty).

Living as we do now in a far more mediatised environment, the issue of 'disrespect' haunts any contemporary re-presentation of individuals. So the over-long lingering on Grace Kelly remains a rare example of the disruptive potential of television, of which there have been few examples since. The technology enables this sustained gaze:

7 Laura Grindstaff, The Money Shot: Trash, Class and the Making of TV Talk Shows, University of Chicago Press, 2002, p. 19.

8 Idem, p. 4.

9 John Ellis, Documentary: Witness and Self-Revelation. Routledge, 2011.

10 John Ellis: 'How to be in public: the case of an early television show,' Celebrity Studies 6,3, 2015, 355-369. 
it is well within the technical affordances of the television apparatus. But for very good social and cultural reasons, television practice has chosen not to take it up for. Sustained close-ups of this sort seem to the modern viewer to be invasive of the person of the observed. This continues to be the case nowadays even on occasions such as this where the whole event is staged for the public, and the subject is a film star, well used to public scrutiny and close-up photography.

Our era has become increasingly aware of (and excited by) the potential of media invasion of privacy. We have become increasingly aware of the complexities of public fascination with public figures. We have become increasingly aware of the problems of concentrating our gaze on women, even when they appear to offer themselves up for the public gaze. Media institutions, and behind them the law courts, continually make judgements about what constitutes 'privacy' and 'respect of privacy' for public figures. It remains an unstable and contentious issue. Even within Europe, media practices and national legislations differ on that issue. Photos of British royalty which are not published in the UK often appear in the magazines of other European countries. Photos and footage of media celebrities which the UK media freely display are judged as invasions of privacy in France and subject to legal redress. British broadcasters are very reluctant to show news footage of dead or dying individuals. Other European broadcasters have no such reservations, judging the impact to be justified by the importance of the story. Europe is not at one in the details ongoing in the debate about media privacy and 'disrespect', but a two minute close-up is not a practice that exists anywhere in mainstream television (though it can, on rare occasions, be found in 'innovative' documentary practices). European practices differ about the detailed implementation of privacy, in other words, but the principle and the concerns that underlie it are shared by all. And as moving image recording becomes more common and more pervasive, many citizens are becoming aware that they, too, might fall into the realm of public scrutiny. When everyday life is increasingly mediatised, who knows who will be next?

\section{Discovery and Access}

This makes these transgressive examples all the more important for understanding our present moment and future choices. Yet discovery of these moments can be a difficult process. For me, it required a dedicated archivist who brought the Plunder programme to my attention as a participant in a study group. In following up, I discovered an Arte documentary about the coverage of the wedding on the INA website, where I was able to purchase a download at negligible cost. It is a carefully researched programme about the background to the newsreel coverage of the wedding, and the role of Prince Rainier's ambitions for TeleMonteCarlo. This article draws heavily on the programme.

However, it appears that the researchers did not locate the telerecording of the event as they do not include any of the TV coverage. It would have powerfully supported their account of the restrictions put on the newsreel coverage by Prince Rainier. The visual material in this documentary concentrated almost exclusively on the newsreel footage. The INA site itself did not reveal the existence of the original TV footage. This was a chance discovery from a Google search using the exact name of the file on the INA Media Pro catalogue, which revealed it as a retransmission in the evening of 19 April 1956 at 20.45. The catalogue lists a 1 hour 45 minute programme with the ID CPF86611535. It reveals that my original source for the footage, the BBC2 Plunder programme, was not as definitive as I had thought. It had edited the material and I had no way of telling that this had happened. The editing had intensified the effect of Grace Kelly's possible tear, but it had also abbreviated the transgressive long close-up that led up to it.

So it seems that, despite all your efforts to open up the archives, Sonja, there is still plenty of work to be done to unearth the riches that lie within. Many of them will be, like the long close-up of Princess Grace, transgressive moments that show how television was a disruptive force in the visual economy of European culture, something whose impact we are still assessing even today. 
J. Ellis, Did Grace Kelly Shed a Tear?

\section{B i o graph y}

John Ellis is Professor of Media Arts at Royal Holloway University of London. His most recent publications are Documentary: Witness and Self-Revelation (Routledge 2011), TV FAQ (IB Tauris 2007) and Seeing Things (IB Tauris 2000). He is chair of Learning on Screen (formerly BUFVC). He was an independent TV producer from 1982-99. His current work involves initiatives to make archival TV material more available and to document the history of technologies in television production. His ADAPT project reunites retired equipment with the people who used to use it. Some of these 'simulations' are accessible at http://royalholloway.figshare.com/ADAPT.

This article was written as part of the ADAPT project funded by the European Research Council (ERC) under the European Union's Horizon 2020 research and innovation programme (grant agreement No 323626). 